\title{
SMART BIN MONITORING SYSTEM FOR SMART WASTE MANAGEMENT
}

\author{
Ahmed Soliman \\ MSc student, University of Miskolc, Institute of Logistics \\ 3515 Miskolc, Miskolc-Egyetemváros, e-mail: ahmed.soli101@gmail.com \\ Mohammad Zaher Akkad \\ PhD student, University of Miskolc, Institute of Logistics \\ 3515 Miskolc, Miskolc-Egyetemváros, e-mail: zaherakkad91@gmail.com \\ Rima Alloush \\ MSc student, University of Miskolc, Institute of Logistics \\ 3515 Miskolc, Miskolc-Egyetemváros, e-mail: rima.alloush33@gmail.com
}

\begin{abstract}
The fourth industrial revolution offers new technologies and solutions to increase efficiency, availability, flexibility, and decrease the economical footprint of manufacturing and service processes. In smart cities, a wide range of Industry 4.0 technologies can be used in the field of road traffic monitoring, health monitoring, and many operations, like the municipal waste collection. Internet of Things makes it possible to reduce the required material handling solutions of municipal waste collection, like loading and unloading, transportation, and warehousing. With smart waste management, no need for trucks to come every day and check every single dustbin if it is full or not as in the traditional situation, therefore the human power, time, cost, and spreading of toxic gas will be reduced. The amounts of the garbage will be monitored by sensors, pollution level by moisture sensor, and an odor sensor. The collected data can also be used to find the optimal path for the truck's drivers. Within the frame of this article, the authors describe an on-line smart bin monitoring system.
\end{abstract}

Keywords: logistics, monitoring, sensors, smart bin, waste collection

\section{Introduction}

The strong need to save the environment from the pollution generally and from the pollution caused by the garbage especially, made the municipalities think seriously in finding an optimal way to collect the waste from the districts of the city with the consideration of the rapid urban development which causes an increase in the generating of various types of waste. The conventional waste collection system lacks access to necessary data about the current amount of the dustbin and its location which means falling throughput and rising waste collection. The technology was the solution, which resulted on the Internet of Things concept for solving the most main problems, Internet of Things also has a main role in smart cities development which include smart waste management component. The smart waste management concept contributes to improving the quality and efficiency of the waste collection process, reducing the cost of collection, saving time by sending the garbage truck to the full dustbin only, and reducing pollution by preventing overflow situations. The proposed project monitors the bin status in real-time 
by displaying the received data from the distance sensors which are located on the top of the bin. Also, these data will be stored in a database for use later in prediction processes. This paper is organized as follows. Section 2 presents a literature review, which summarizes the research background of smart bin monitoring. Section 3 describes the implementation of a smart bin monitoring system. Section 4 presents the expected results from a cyber-physical municipal waste collection system point of view. Conclusions and future research directions are discussed in Section 5.

\section{Literature review}

The fourth industrial revolution has a great impact on today's manufacturing and service processes [1]. A wide range of Industry 4.0 technologies, like new identification solutions or digital twin applications, can be used to improve the efficiency, availability, and flexibility of industrial processes [2].

IoT garbage monitoring system was created [3] for monitoring the status of the bins and sending an alert in case it is full for trying to reduce the air pollution and human powers and cost. This system is using the ultrasonic sensor that is connected to the ARM microcontroller and ESP8266 Wi-Fi module for sending data. The data will be displayed on LCD that interfaces with the microcontroller and displayed also on ThingSpeaker by ESP8266 Wi-Fi module. Jain et al designed and implemented a Smart solid waste monitoring and collection system based on IoT [4]. The goals of the proposed system are making waste management faster, smart, consume less power, and save fuel. The used hardware in this system are Renesas RL 78 microcontroller that is connected with all hardware parts and consider sensors output as input then process it and output the corresponding order, Ultrasonic sensor for monitoring the amount of the waste, force sensor for detecting the weight of the dustbin, Passive Infrared Sensors (PIR) sensor to make the bin is opened in case the bin is not full, Red LED for a filled bin, the green LED for the empty bin, LCD to display the status of the bin, GPRS provides the communication between the microcontroller and web server that keep the bin status and update it when needed, GPS provides the location of the bin to Android application. when the user opens the application, the webserver will send the status of bins, according to this information the user can select the suitable and empty bin to throw the waste. After the process is finished, the status will be updated on the webserver. Instead of focusing on the waste collections, Malapur et al applied another way to reduce more cost and time [5]. The used technologies are Ultrasonic sensor, Arduino microcontroller, GSM/GPRS, and buzzer to avoid the overflow status. The data that is sent to the server-side by GSM/GPRS is stored in the database. By considering this data the optimal path is generated by the Genetic algorithm.

Ravale et al tried to prevent the dustbin from overflowing [6] by using two IR sensors, when the bin is half full, the first sensor will send an alert and when the bin is full, the second sensor will send the final alert. The alert is sent by Arduino microcontroller to Raspberry Pi then to the municipality. In every cycle, the sensor status in the simple database is reset to empty status. Yusof et al proposed Smart Waste Bin with Real-Time Monitoring System [7], the proposed system used two bins for wet and dry waste, each bin contains an ultrasonic sensor to monitor the waste amount, a microcontroller to process data then send it to a cloud server by RFID. After that, the data will be displayed on the web and mobile applications in real-time and provide the shortest path according to the android application holder (truck driver). The collected data is used in ThingSpeak to process it then analyze it to show the status of the bin on the map. Hassan et al designed a project to monitor the waste level and send status in real-time [8]. The project is an Ultrasonic sensor attached to the top of the bin to sense the waste level then the data will be sent to a microcontroller, which in turn sends it to the database by Wi-Fi module (ESP8266), and mobile application that can access the database to scan the status of the bins. Here, the Genetic algorithm was used again. Chaudhari et al. tried to find the optimal path by filling the bins randomly 
then sending data for every bin like the bin position, the bin status, the bin size, etc. Finally, a Genetic algorithm was applied according to these data [9]. Soh et al designed Smart Waste Collection Monitoring and Alert System via IoT [10], the project aims to prevent the overflowing of the bin, as when the distance between the ultrasonic sensor and the wase level reaches $4 \mathrm{~cm}$ or less, Ubidots device will send alert to the concerned worker.

A new municipal waste collection system based on advanced Industry 4.0 technologies is demonstrated in $[11,12]$. As Figure 1. shows, the suggested system includes dealing with the waste starting from the source points until the waste treatment facilities.

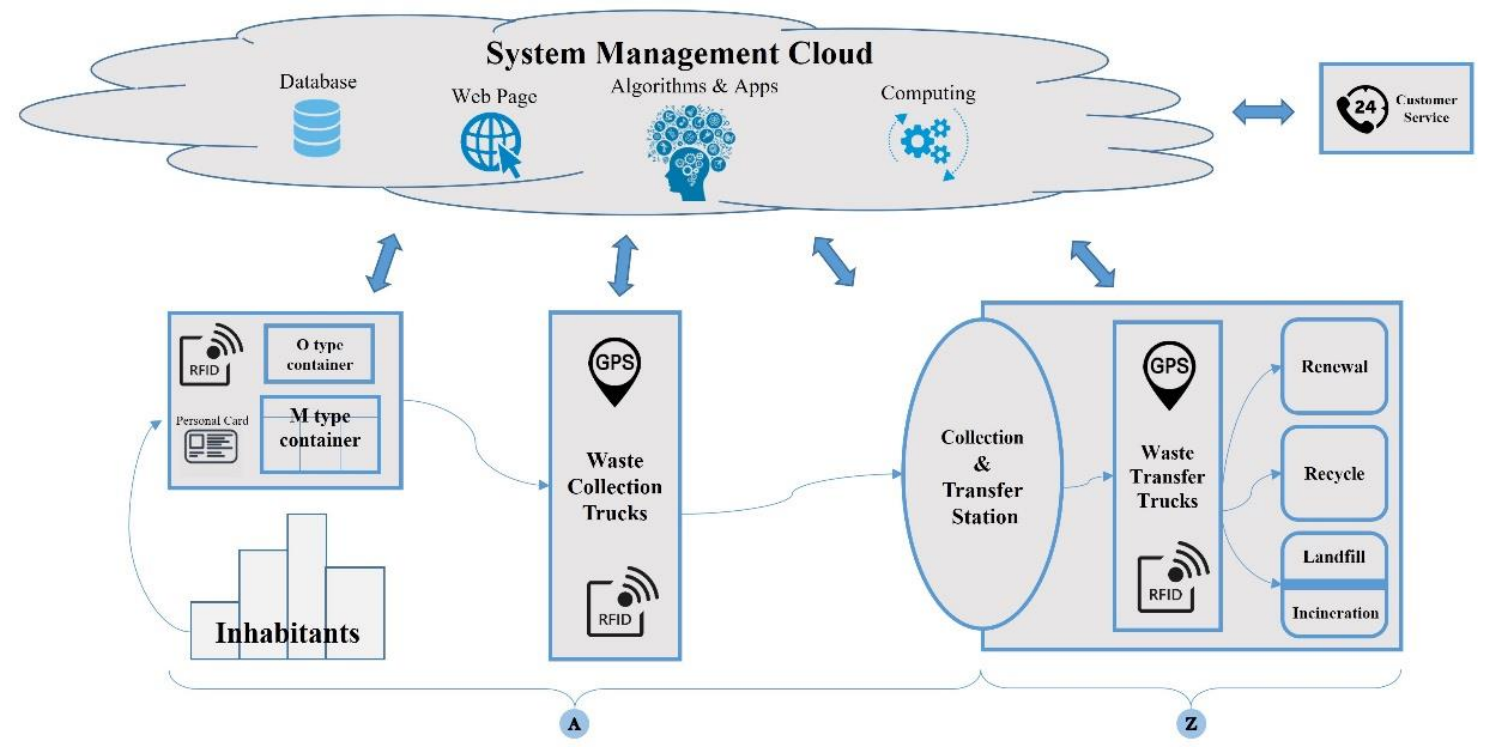

Figure 1. Municipal waste collection system [11,12]

Ziouzios et al design a new smart bin to avoid the overflowing using LoRa network [13]. They also tried to use low power by making the system sleep as long as the cap is closed. The project consists of a microcontroller, an ultrasonic sensor to detect the level of waste in the bin, a pressure sensor for cap status, a temperature sensor for an emergency in case of fire, Libelium SX1272 module to send the data to LoRa gateway, and Arduino IDE used for software implementation. IoT based Smart Bin [14], Praveen et al used two Ultrasonic sensors, first one to detect the level of the dustbin, the second to open the cap of the bin by servo motor connected to this sensor, ESP8266, and Raspberry Pi. The project supposes that every house has its dustbin, if someone approaches the dustbin, the dustbin will be opened in case it is not full, otherwise, it will remain closed. Then when the dustbin is full, the data will be sent to Raspberry pi by the Wi-Fi module, then the data will be displayed on the monitor. Xenya et al proposed a system that monitors the dustbins' status in real-time and provides an optimized route [15]. The data is sent regularly to the cloud-based database. When the level of waste reaches the threshold, the waste agent is provided with the bin status and the optimized route made by Google map service, in case failing of sending the optimal route, he will receive SMS including the link to the optimal route. At the same time, the administrator keeps monitoring the process through management applications until the work is done, then the data will be reset by the admin. 
The proposed system of Tamakloe et al [18] is distinguished from the previous system in that it provides the user with the weight of the bin's waste. Also, there is a compactor to reduce waste volume. The sensor monitors the waste level, when the waste reaches half or more of the dustbin capacity, the microprocessor activates the compactor to compress the waste. The data is sent regularly by the GSM module to cloud platforms then to the web application. This application displays the status of bins, their weights, and generates an optimal route to full bins by Google Map Service.

As Figure 2. shows, Cservenák and Bányai introduce a further development of a standard commercial waste bin. This dustbin is able to detect its current load, open-close the cover automatically, and remote access the load level using an online interface $[16,17]$.

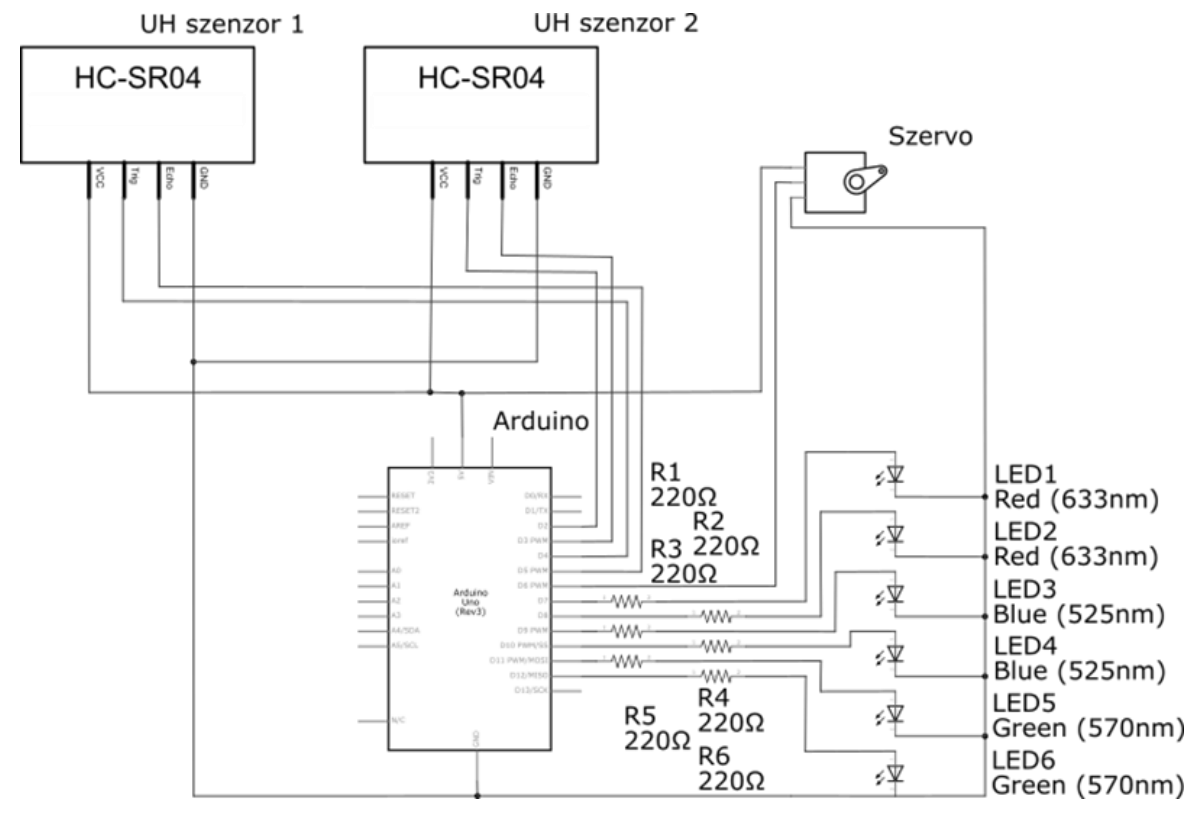

Figure 2. Circuit diagram of the smart bin [16]

Dubey et al used machine learning to predicate the bin status and send an alert message [19]. The authors suppose three parameters to the test, dustbin level, metal level, and poisonous gas level. They mention that the Random Forest algorithm (RF) has the best accuracy. Jabar et al supposed a solution to manage the dustbins [20]. The supposed system provides web applications and mobile applications to monitor all the dustbins' status in every area, then send the trucks to the full bins at a suitable time. Tripathi et al proposed a smart bin using IoT [21], the proposed system was tested in one area and it contains sensors to monitor the dustbins' status and collect the data in real-time. Waste management improvement using IoT was proposed [22] for monitoring the dustbins status and separating the waste according to its category by using several sensors, then sending an alert to clean the full dustbins. Shetty et al propose a low-cost implementation of smart waste management [23]. The proposed system consists of two sub-systems, the first one to separate the waste to the wet group or the dry group, and the second subsystem to detect the level of waste in every dustbin. The dustbins status is displayed on a mobile application in real-time.

Improve smart waste management to preserve tourist attractions in Yogyakarta in IoT Environment was created [24], the system provides sensors to monitor the dustbins status, two categories of the 
dustbins, one for the wet waste, and another for the dry waste, there are three servos, every dustbin has servo is attached to its lid, and one to carry the waste to its category dustbin. All the servos are working according to the output of the moisture sensor. The system also provides for the tourists an optimal route to the nearest dustbins, the optimal route is created by the steepest ascent hill algorithm. Jaikumar et al also propose a system to segregate the waste and monitor the status of the bins [25]. In this system, Message Queuing Telemetry Transport (MQTT) has been used for transmission. Ranjitha et al describe an application, that manages the waste in the dustbins of the city. The application was provided with a network of sensors to send data, then process it and analyze it in real-time.

\section{Implementation of a smart bin monitoring system}

The web development hierarchy is as follows: Client-side (Front-end development) and Server-side (Back-end development). Front-end development is client-side, it includes every component that can be seen and communicated directly by the user (client) such as images, colors, styles, graphs, tables, buttons, live animations, navigation menus, etc. to get a good user experience, the developer has to check the performance and responsiveness of the front-end objectives. The most used languages for front-end development are HTML, CSS, and JavaScript (JS).

Back-end development is the server-side that contains server, application, and database. It is the part that cannot be seen and cannot be accessible by the client. It stores the data, controls the components of the front-end part, and ensures that the front-end receives the data correctly. There are vast languages to build the back-end portion such as python, java, PHP, C++, etc. The smart bin monitoring design component structure is shown in Figure 3.

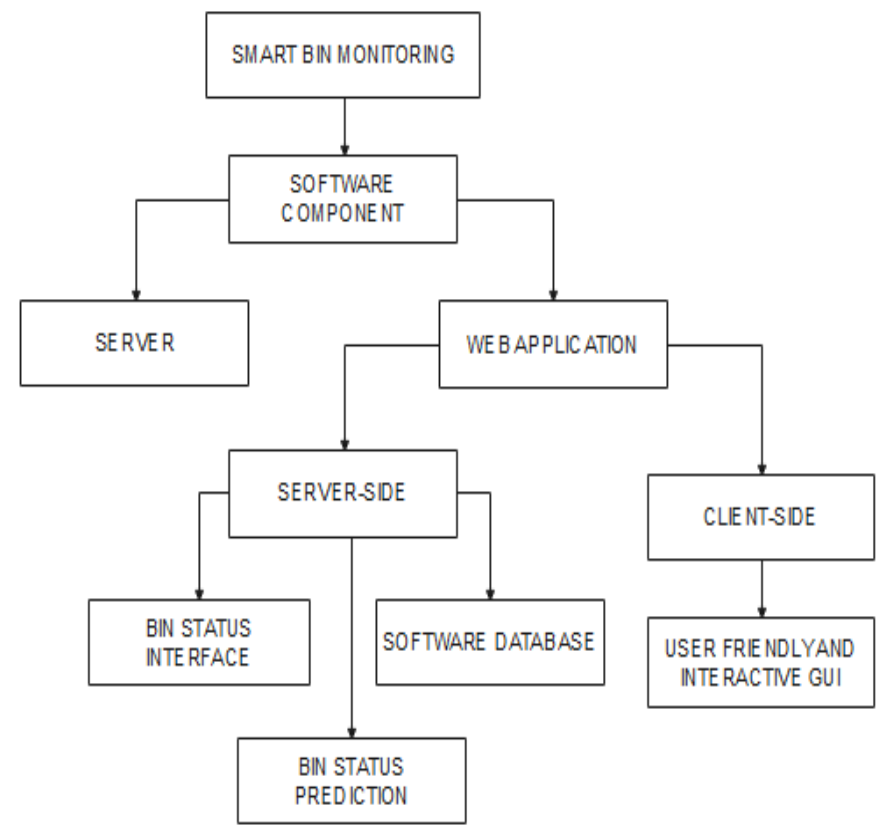

Figure 3. Smart Bin Monitoring design component structure 
We suggest here, it starts from the server side that works 24 hours per day and sends the sensor data every 30 seconds to the web application. The web application is the second section of the software that consists of back-end and front-end development.

The sent data is picked up by the server-side to process and display it on the client-side. The data will be stored in the database when it indicates that the bin is full which can be analyzed later to predict the bin status in the coming days (see Figure 4).

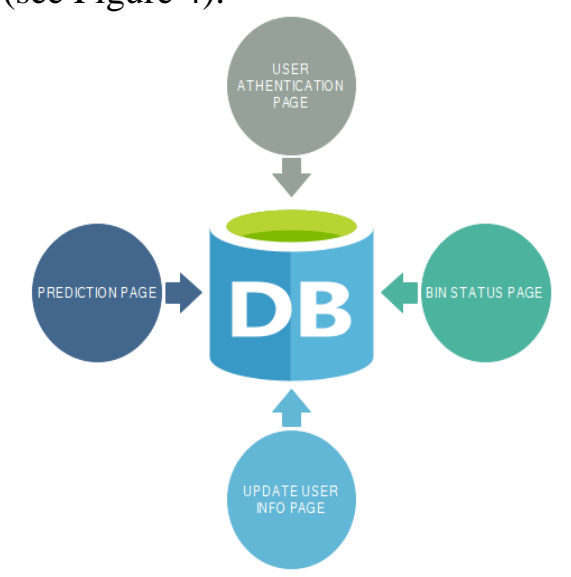

Figure 4. Server-side Architecture

In this software, our own server is created with Raspberry Pi using python. Python is an objectoriented programming language. It is the most popular which is used in different disciplines. Python can be used to build web, mobile, and desktop applications, as well as software testing, etc. in addition to, the large ecosystem of libraries, frameworks, and tools. The web application has been created to be a user friendly and interactive interface which can cover all requirements to monitor the bin status and save its information in real-time. The front-end has been designed by Hypertext Markup Language (HTML) which help in building the web pages of the website, Cascading Style Sheet (CSS) that uses to create an attractive website which can -by CSS- change the background color and font, etc. the last language used in this website which is a real programming language, unlike HTML and CSS. JavaScript is used in our website to respond to real-time data exchange between the front-end and back-end. The back-end section has been created by flask which is a micro web framework, and it is one of the most popular modules of python for the web developer. The most advantages are easy to use and create an application, quick to learn, and fast execution. The used database is SQLALCHEMY which is a python SQL toolkit and Object Relational Mapper (ORM).

In our database, two stored tables cover the user data and the bin status data. The user table includes the username, email, profile picture, and password. The second table has two columns which are Status and Day. Every day, the bin status is stored for two times at a specific time, and the day column refers to the day when the status was stored.

The login page is the welcome page, where the valid email and password must be typed by the user to be redirected to the home page which will display the bin status. In case the user forgot the password for authentication, there is a choice to edit the password by clicking on the forgot password link. The edit password link, which is valid for 30 minutes, will be sent to an email user.

The user can update his/her data (username, email, profile photo) on the user page. Figure 5. represents the update page. 
The user is two types, normal user, and admin user. The previous user mentioned is normal, while the admin has the same privileges as the normal user, in addition to the ability to register the new client and predict the bin status. Figure 6. illustrates admin privileges.

In the navigation bar, there is an additional link to register a new member and another link to predict the bin status. The received data from the raspberry pi (server) will be displayed on the home page in a real-time chart which can update the bin status in real-time without any need to refresh the page. The displayed chart results from integrating the web application with the FusionCharts APIs. Figure 7. represents the home page.

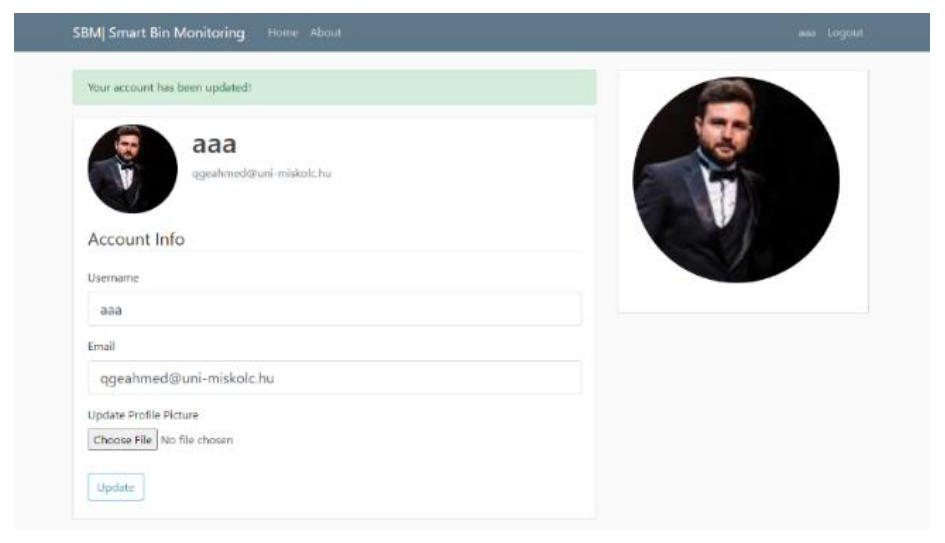

Figure 5. Update page

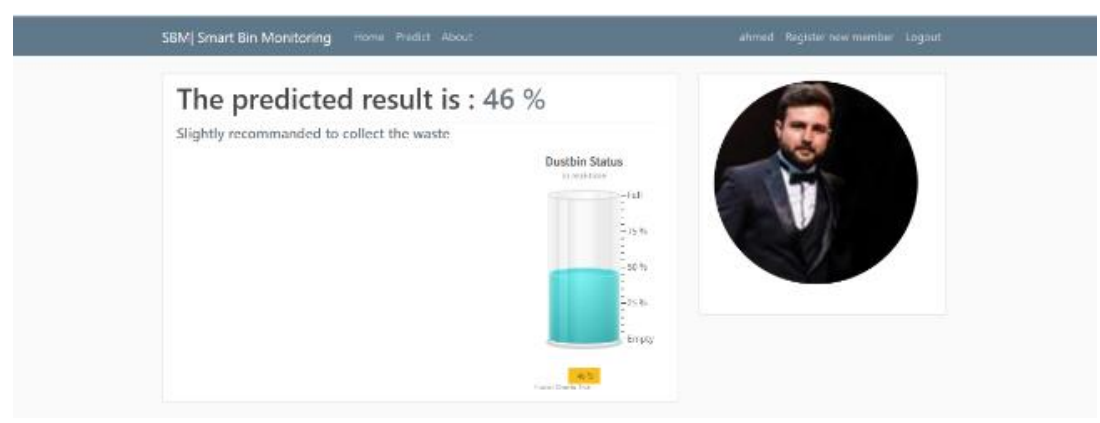

Figure 6. Admin privileges

The stored data in the database that was explained in the application database section is used in the prediction process. When the admin presses the Predict link, the updated data in the status bin table will be exported to CSV file as a dataset using CSV library. By exporting the data every time asking to predict, the results are ensured that more real according to the last updated, and the previous dataset will be removed automatically. The used algorithms for the prediction process in this application are $\mathrm{K}$ Nearest Neighbors (KNN), and Random Forest algorithms. When the admin chooses the day, which is wanted to predict, then the result will be displayed according to every algorithm which was mentioned before. 


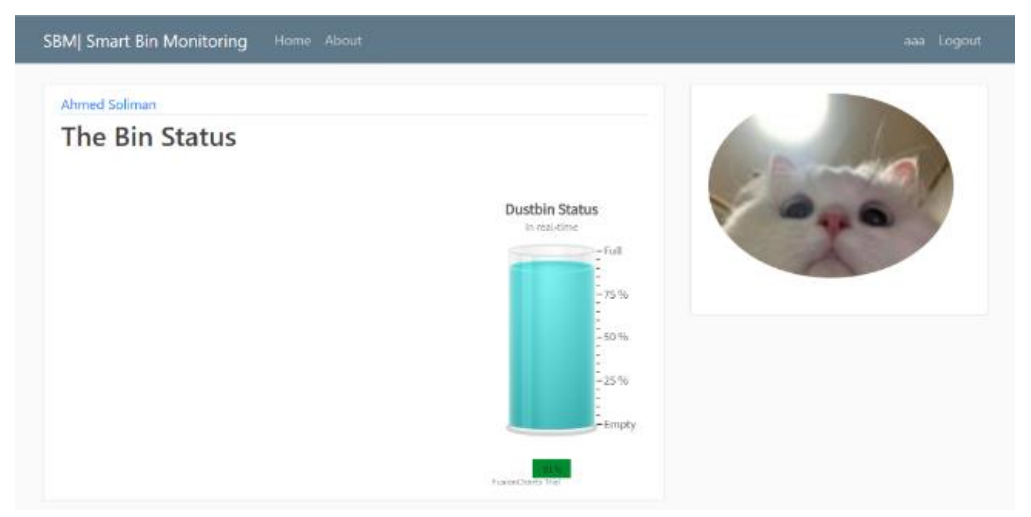

Figure 7. The bin status

\section{Expected results}

The designed application benefits cover the achieving of clean and green surrounding without the stinky odor of wastes which produce a healthy environment and keep cities more attractive. the monitoring of the bin status in real-time which avoid the insect infestation and spreading the diseases that result from the decomposition of the accumulation waste, reducing the human power to handle the garbage by reducing the times of collecting the garbage which is limited to the full dustbins cases thus time and cost will be reduced, improve management and resources which progress step toward the smart city, decrease traffic flow because of less waste collection trucks on the roads. The prediction part of the application makes the waste management system more efficient, which can provide valuable information based on sensor data such as predicting when the bin status will be full. If the prediction system in this application is improved and used vary and real data such, the Urban Development and demographic growth can be predicted

\section{Summary and conclusions}

In this article, poor waste management has been discussed and its effects such as releasing toxic gas and spread diseases have been clarified. Also, the Internet of Things concept has been explained by mentioning the best IoT application which is the smart city, and its huge role in improving the waste management system to reduce the cost, time, and toxic gases. The designed web application has the authentication conditions for the users and fulfills the requirements to improve the waste management system by monitoring the bin status in real-time. Also, the designed application includes a machine learning field which helps to predict the bin status. The used machine learning algorithms are K Nearest Neighbors (KNN), and Random Forest algorithms. The data source of the prediction application is the distance sensor which calculates the distance between the top of the dustbin and the waste level. The sensor data is transferred by the raspberry pi over the internet, which is connected to the application by the server, this server was created by socket programming. The Prediction can be improved by increasing the number of sensors to sense many factors which can be used in the prediction such as dustbin temperature, waste weight, humidity, etc. with the mentioned data, the system can result in more prediction accuracy. Finally, the stored data in the designed application was virtual data which contributed to simulate a waste management system. To have real data, the bin must be monitored for 20 weeks at least to gain a satisfying prediction. In general, the web application can be expanded to 
cover the waste collectors (trucks) by using the prediction to find the optimal route, the mobile application also can be created to improve the notification system which can send notification whether the application is opened or closed.

\section{Acknowledgments}

The described research was carried out as part of the EFOP-3.6.1-16-2016-00011 "Younger and Renewing University - Innovative Knowledge City - institutional development of the University of Miskolc aiming at intelligent specialisation" project implemented in the framework of the Szechenyi 2020 program. The realization of this project is supported by the European Union, co-financed by the European Social Fund.

\section{References}

[1] Matyi, H., Veres, P., Banyai, T., Demin, V, Tamas, P. (2020) Digitalization in Industry 4.0: The Role of Mobile Devices. Journal of Production Engineering 23(1):75-78. http://doi.org/10.24867/JPE-2020-01-075

[2] Lasi, H., Kemper, H.G., Fettke, P., Feld, T., Hoffmann, M. (2014) Industry 4.O. Business and Information Systems Engineering 6(4):239-242. https://doi.org/10.1007/s12599-014-0334-4

[3] Mustafa M.R, Ku Azir K.N.F. (2017) Smart Bin: Internet-of-Things Garbage Monitoring System. MATEC Web of Conferences 140:01030. https://doi.org/10.1051/matecconf/201714001030

[4] Jain, A., Bagherwal, R. (2017) Design and Implementation of a Smart Solid Waste Monitoring and Collection System Based on Internet of Things. 8th International Conference on Computing, Communication and Networking Technologies, pp. 1-5, Delhi, India, IEEE, 17 December 2017. https://doi.org/10.1109/ICCCNT.2017.8204165

[5] Malapur, B.S., Pattanshetti, V.R. (2017) IoT based Waste Management:An Application to Smart City. International Conference on Energy, Communication, Data Analytics and Soft Computing, pp. 2476-2486, Chennai, India, IEEE, 21 June 2018. https://doi.org/10.1109/ICECDS.2017.8389897

[6] Ravale, U., Khade, A., Patel, N., Chaure, S. (2017) Smart trash: An Efficient Way for Monitoring Solid Waste Management. International Conference on Current Trends in Computer, Electrical, Electronics and Communication, pp. 1135-1137, Mysore, India, IEEE, 6 September 2018. https://doi.org/10.1109/CTCEEC.2017.8455049

[7] Yusof, N.M., Zulkifli, M.F., Yusof, N.Y.A.M., Azman, A.A. (2018) Smart Waste Bin with RealTime Monitoring System. International Journal of Engineering and Technology, 7(2.29): 725-729. https://doi.org/10.14419/ijet.v7i2.29.14006

[8] Hassan, H., Saad, F., Abdul Aziz, N.F. (2018) Waste Monitoring System based on Internet-ofThing. IEEE Conference on Systems, Process and Control, pp.187-192, Melaka, Malaysia, 2 Mai 2019. https://doi.org/10.1109/SPC.2018.8704142

[9] Chaudhari, M.S., Patil, B. (2019) IoT based Waste Collection Management System for Smart Cities: An Overview. 3rd International Conference on Computing Methodologies and Communication, pp. 802-805, Erode, India, 29 August 2019. https://doi.org/10.1109/ICCMC.2019.8819776 
[10] Soh, Z.H.C. Husa, M.A.A., Abdullah, S.A.C., Shafie, M.A. (2019) Smart Waste Collection Monitoring and Alert System via IoT., IEEE 9th Symposium on Computer Applications \& Industrial Electronics, pp.50-54, Malaysia, IEEE, 27-28 April 2019. https://doi.org/10.1109/ISCAIE.2019.8743746

[11] Akkad, M.Z., Bányai, T. (2019) Cyber-physical waste collection system: a logistics approach. In: Szita Tóthné, K., Jármai, K., Voith, K. (eds.) Solutions for Sustainable Development: Proceedings of the 1st International Conference on Engineering Solutions for Sustainable Development. London, Egyesült Királyság / Anglia: CRC Press, pp. 160-168. https://doi.org/10.1201/9780367824037-21

[12] Bányai, T., Tamás, P., Illés, B., Stankevičiūtè, Ž., Bányai, Á. Optimization of Municipal Waste Collection Routing: Impact of Industry 4.0 Technologies on Environmental Awareness and Sustainability. International Journal of Environmental Research and Public Health 16(4):634. https://doi.org/10.3390/ijerph16040634

[13] Ziouzios, D., Dasygenis, M. (2019) A Smart Bin Implementation using LoRa, 4th South-East Europe Design Automation, Computer Engineering, Computer Networks and Social Media Conference, pp.1-4, Piraeus, Greece, 20-22 September 2019, IEEE, https://doi.org/10.1109/SEEDA-CECNSM.2019.8908523

[14] Praveen, A., Radhika, R., Rammohan, M.U, Sidharth, D., Ambat, S., Anjali, T. (2020) IoT based Smart Bin: A Swachh-Bharat Initiative. International Conference on Electronics and Sustainable Communication Systems, pp. 783-786, Coimbatore, India, IEEE, 2-4 July 2020. https://doi.org/10.1109/ICESC48915.2020.9155626

[15] Xenya, M.C., D'souza, E., Woelorm, K.O.D., Adjei-Laryea, R.N., Baah-Nyarkoh, E. (2020) A Proposed IoT Based Smart Waste Bin Management System with An Optimized Route: A Case Study of Ghana. Conference on Information Communications Technology and Society, pp.1-5, $\begin{array}{lllll}\text { Durban, South } \quad \text { Africa, IEEE, } & \text { 11-12 }\end{array}$ https://doi.org/10.1109/ICTAS47918.2020.234005

[16] Cservenák, Á., Bányai, T. (2020) SmartBin fejlesztése kiber-fizikai hulladékgyüjtési rendszer kialakításához. Multidiszciplináris Tudományok: A Miskolci Egyetem Közleménye 10(3):91-95. https://doi.org/10.35925/j.multi.2020.3.10

[17] Cservenák, Á., Bányai, T. (2020) SmartBin development for cyber-physical waste collection. Proceedings of the $13^{\text {th }}$ International Doctoral Students Workshop on Logistics. June 16, 2020 Magdeburg, Germany. pp. 45-48.

[18] Tamakloe, C., Rosca, E.V. (2020) Smart Systems and the Internet of Things (IOT) For Waste Management. IEEE International Conference on Computational Intelligence and Virtual Environments for Measurement Systems and Applications, pp.1-6, Tunis, Tunisia, 22-24 June 2020. https://doi.org/10.1109/CIVEMSA48639.2020.9132968

[19] Dubey, S., Singh, M.K., Singh, P., Aggarwa, S. (2020) Waste Management of Residential Society using Machine Learning and IoT Approach. International Conference on Emerging Smart Computing and Informatics, pp. 293-297, Pune, India, IEEE, 12-14 March 2020. https://doi.org/10.1109/ESCI48226.2020.9167526

[20] Jabar, H., Hassan, R., Sadeq, A.S. (2020) A New Smart Waste Managing System. International Conference on Computer Science and Software Engineering,pp. 209-214, Duhok, Iraq, IEEE, 1618 April 2020. https://doi.org/10.1109/CSASE48920.2020.9142068 
[21] Tripathi, D.K., Dubey, S., Agrawal, S.K. (2020) Survey on IOT Based Smart Waste Bin. IEEE 9th International Conference on Communication Systems and Network Technologies, pp. 140144, Gwalior, India, IEEE, 10-12 April 2020. https://doi.org/10.1109/CSNT48778.2020.9115793

[22] Jagtap, S., Gandhi, A., Bochare, R., Patil, A., Shitole, A. (2020) Waste Management Improvement in Cities using IoT. International Conference on Power Electronics \& IoT Applications in Renewable Energy and its Control, pp. 382-385, Mathura, Uttar Pradesh, India, 28-29 February 2020. https://doi.org/10.1109/PARC49193.2020.236631

[23] Shetty, S., Salvi, S. (2020) SAF-Sutra: A Prototype of Remote Smart Waste Segregation and Garbage Level Monitoring System. International Conference on Communication and Signal Processing, pp. 363-367, Chennai, India, 28-30 July 2020. https://doi.org/10.1109/ICCSP48568.2020.9182408

[24] Arinta, R.R., Watomakin, D., Suyoto, S. (2020) Improve Smart Waste Management to Preserve Tourist Attractions Yogyakarta in IoT Environment. International Conference on Smart Technology and Applications, pp.1-6, Surabaya, Indonesia, IEEE, 20 February 2020. https://doi.org/10.1109/ICoSTA48221.2020.1570610836

[25] Jaikumar, K., Brindha, T., Deepalakshmi, T.K., Gomathi, S. (2020) IOT Assisted MQTT for Segregation and Monitoring of Waste for Smart Cities. 6th International Conference on Advanced Computing and Communication Systems, pp. 887-891, Coimbatore, India, IEEE, 6-7 March 2020. https://doi.org/10.1109/ICACCS48705.2020.9074399 